\title{
The Museum as Information Space: Metadata and Documentation
}

\author{
Trilce Navarrete and John Mackenzie Owen
}

\begin{abstract}
Although museums vary in nature and may have been founded for all sorts of reasons, central to all museum institutions are the collected objects. These objects are information carriers organized in a catalogue system. In this chapter, the museum will be conceived as an information space, consisting of an information system related to different methods of reasoning. We will highlight the new possibilities offered by digital technology and the changes brought by the way in which visitors come into contact with objects. Our central claim is that the visitor moved from being onsite within the museum's information space to being outside the museum in the online information space of the Internet. This has fundamental implications for the institutional role of museums, our understanding of metadata and the methods of documentation. The onsite museum institution will, eventually, not be able to function as an institutional entity on the Internet, for in this new information space, objects, collections and museums, all function as independent components in a vast universe of data, side by side at everyone's disposal at anytime. Potentially, users can access cultural heritage anytime, anywhere and anyhow.
\end{abstract}

T. Navarrete $(\bowtie)$

University of Southern Denmark, Campusvej 55, Odense 5230, Denmark

e-mail: trilce.navarrete@gmail.com

J. Mackenzie Owen

University of Amsterdam, Amsterdam, Netherlands

e-mail: MackenzieOwen@gmail.com 


\section{The Museum as Information Space}

Collected objects support entertainment, learning and research. Objects are collected and preserved with the purpose "to represent, to reconstruct, or to demonstrate a physical or conceptual phenomenon" (e.g., to represent a period, a place, a person, an order, a set of values, a specific idea, or a moment in time) (Buckland 1997: 805). As collections are formed, the objects' original context is replaced by a new one. The new context is part of a space in which the museum professional exhibits objects to guide the information transmission process. As such, the object's function is to inform a person observing it: objects are information carriers (Buckland 1997: 805; Leone and Little 2007: 362). The information they convey depends on the observer's 'reading' of the object, based on acquired rules of interpretation and methods of reasoning. So, for instance, a painting may be 'read' differently by a painter (observing colour and brushstroke), an art historian (determining cultural and historical value) and a chemist (inspecting mineral composition).

Knowledge results from reasoning about objects, that is, from the capacity to make sense of things based on learnt rules and systems of relations (Boekhorst et al. 2005; Hooper-Greenhilll 1992; Marty 2008; Navarrete and Mackenzie Owen 2011). As such, the museum is a space of communication. Traditionally, museums communicated with their visitors using what Hooper-Greenhill describes as the transmission model. She writes:

The 'transmission' model of communication understands communication as a linear process of information-transfer from an authoritative source to an uninformed receiver. Knowledge is seen as objective, singular and value-free. The receiver of the message to be communicated is conceptualized as open to the reception of the message, which is received more or less efficiently, and in the same way by all (Hooper-Greenhill 2007: 560).

After it had been questioned whether this transmission model indeed worked, some museums opted for a conversation model in which the audience participates and is able to attach meaning to the observed objects (Hooper-Greenhill 2007: 562). The more prominent role of the visitor in the museum space is related to the awareness of the constructivist nature of knowledge, which has already made the lay public demand alternative interpretations, explore new meanings and to critically confront the experts with their own views (Hooper-Greenhill 2007: 572). Museums, in turn, have presented alternative narratives to one object or one exhibit through temporary exhibits or multiple guided tours (McClellan 2008). That is, as objects get moved from one exhibition to another, curators can chose to present the same object as part of an artist's oeuvre, as illustration of a genre, or as context to highlight the work of another artist. Similarly, guided tours may highlight a different aspect of the work within the same exhibit to best respond to the public's needs (e.g. school tours).

These museums shape and control their information space through a series of decisions: selecting objects, placing objects in a specific context (next to other objects as part of a collection or exhibition), classifying and applying labels to them, and using specific methods of research and publication. Also the museum 
building, its architecture and gallery design (e.g., lighting, wall colour, cases and stands), the routes to be taken, its guided tour and use of text labels, are all means at the museum's disposal to determine what information an object carries and transmits. In the onsite viewing context, the 'reading' of objects is constrained by the museum space providing the context in which to reason about the object. The process of allocating a context to an object is deeply ingrained in the work process of museums, both in the back end through object ordering and classifications as well as in the front end or exhibition space. In this respect, the history of object display is also important, for it may reveal systems of organization and thought which help to determine how to 'read' objects (Bennet 1992, 1995; Grognet 2007; Noordegraaf 2004).

\section{The Polysemic Nature of Objects}

Objects are polysemic. That is, the information carried by an object is diverse and changes over time due to such things as reclassification, becoming part of a temporary exhibition, or changing collections because of object repatriation, war, deaccessioning (disposal, exchange or sale), or other forms of organizational change (Hooper-Greenhill 2007; McClellan 2008). But how deliberate are the choices that museums make about the meaning of their objects; and how did they construct their information system to order and classify their objects as collections grew? Until recently, museums have worked with taxonomies and classification systems reflecting differences between museum types and academic disciplines, without being fully aware of what such systems excluded (Legêne 2008). David Vance reported in 1974 that the use of controlled vocabulary can be too specific and limit the polysemic nature of objects:

Does France include Martinique? Tahiti? Did it formerly include Algeria? How does the sense of this word change in a medieval context? Does it always include Burgundyretroactively? What will be the consequences of calling Picasso Spanish but including him in the School of Paris? (Parry 2007: 40).

The polysemic nature of the object as information carrier has been limited by knowledge documentation systems based on 'flat files' and other systems, linking information to an object but isolating it from other objects and other object files at the same time. The desire to create structured vocabularies through thesauri, taxonomies and classification systems developed in academic disciplines, further limited the possible information value of objects (Bearman 2008; Hooper-Greenhill 2007). As museum professionals gained awareness of the polysemic nature of objects in relation to their own organizational structure and work processes, documentation systems evolved in systems capturing information related to the history of the objects in museum spaces. Awareness of the importance of this sort of information increased with the adoption of computers in the heritage domain. So now the question is: what happens to the object, the collection and the museum as 
they enter the online information space? And what role has metadata to play in this transition?

\section{Metadata and Information Management}

Today we expect collection information management systems to support interpretations that may change over time. Information systems must allow for multiple perspectives and scholarly interpretations, and accommodate different vocabularies for different types of users (Bearman 2008; Marty and Jones 2008). Managers, for example, have different information needs than researchers, who in turn want other information from the information management system than curators and the interested public. The adoption of the computer meant a new phase in the history of museum documentation. The concept of metadata became central.

Metadata is information about the object as information carrier. Where museum objects carry external knowledge, metadata may be said to be the internal knowledge of the object (Mackenzie Owen 2007). The internal knowledge (metadata) of a book for example, consists of the number of pages, information about the author and the publisher, date and place of publication, the table of contents and the index; from a metadata perspective, the object's external knowledge would be the thesis that is argued for.

Documenting objects is complex for several reasons. Objects are polysemic in nature, they are connected to other objects and other collections, and objects collect a history as collections, exhibitions, research and preservation techniques develop and change over time. To accommodate the documentation process, specialized metadata categories are distinguished, such as descriptive, administrative, technical and preservation metadata (Baca et al. 2008; Beumer 2009), ${ }^{1}$ including so-called paradata, that is, metadata enabling the documentation of "intellectual capital generated during research" (see London Charter Glossary). ${ }^{2}$ These metadata categories structure the content management architectures, enabling a better management of diverse information sources, alternative readings of objects, and the multiple uses of the object. ${ }^{3}$

\footnotetext{
${ }^{1}$ It has been argued that digital objects and metadata are complementary 'goods' and therefore produced and consumed simultaneously. See Navarrete (2013), for an application of economic theory to digitization of heritage collections.

${ }^{2}$ Drew Baker proposed using the term paradata to document the process of data interpretation in the construction of 3D visualizations for research and dissemination to guide the London Charter (2009), an initiative to develop best practice. Strictly speaking, paradata refers to "documentation of change in collection information by adding new records while keeping the previous ones," including interpretation of sources in the process of visualization (Navarrete 2013: 252).

${ }^{3}$ Content management systems are part of information architecture, responsible for giving structure, methods, and design to the organization of digital information (Wikipedia 2015). Information architecture refers to the use of physical space to order things, as museums have done with their objects and their information. Parry (2007) argues that the museum institution is the metonym of a universe of knowledge.
} 
It is the metadata attributed to the objects that enables discoverability via crossreferences, hyperlinks, multiple interpretations, and so on, all within one database. Objects and their metadata can be linked to other objects and their metadata enriching each other's information dimension. Links increase in direct relation to the metadata attributed to the objects. That is, administrative metadata can complement the technical dimension of the objects, in turn enhanced by descriptive metadata. The potential links available when linking to other databases expands exponentially.

Objects always require metadata in order to function as information carriers, that is, as documents, for it is the metadata that situates the object in both a material and an information context. Finally, we should note that that collections, which are always more than arbitrary sets of objects, too require metadata to support interpretation and contextualization: collections are also objects. As such, an object may be interpreted differently when part of a collection made by an artist, a collector or a national museum. Moreover, the meaning of the collection as a whole, as documented by its metadata, will in part govern the interpretation of the object's belonging to the collection. The same applies at an even higher level to the museum as a collection of collections or supra-collection. Some information management system providers are exploring visualization of information that consider the entire collection as object made of multiple units which can be organized through filters (e.g. colour, chronology, alphabetically, geographically, by related individual, by related event). These systems are based on linking objects to multiple types of information (e.g. location, individuals, events) to facilitate navigation while reinforcing object contextualization. ${ }^{4}$ This allows flexibility in object reading. In a digital world, access to an individual object can follow a path from (metadata about) the museum, to (metadata about) a specific collection, to (metadata about) an individual object.

\section{A New Information Space}

Embracing the Internet, museum collections and single objects are becoming increasingly accessible in digitized form. Technology allows for complex information dimensions, however, in reality, digitization strategies still tend to focus on access to museum collections through images with a brief title (subject) label, thus using a restricted set of possible metadata. Because of this, online collection databases on the Internet lack access to the rich set of contextual and interpretational clues that visitors normally encounter in physical onsite museums. On site, an object is presented within a set of objects, generally with an introductory text and

\footnotetext{
${ }^{4}$ An example can be found at the Microsoft Live Labs Pivot visualization of images and Europeana's Linked Open Data (LOD) approach to structure data following the Resource Description Framework (RDF), which identifies the object, its characteristics and relations based on a subject, predicate, object format.
} 
accompanied by a guided tour, all in addition to the brief label next to it. The informational value of digitized objects is thus severely constrained, not because of the limitations of digital technology, but because of the museum's policy decisions regarding digitization.

Establishing a context for digital collections online is an entirely different process from what museums and their visitors are used to. Onsite, museums control the environment in which the visitor can observe the object by giving it a specific context and the same object transmits different information when it is part of a cabinet of curiosities, a national gallery or a zoo. By giving the object a specific set of metadata, the information carrying potential of the object is restricted. Online, alternative contexts are possible as multiple metadata can be displayed. Furthermore, the user is no longer inside the information space provided by the museum but free to explore any context she likes, following personal interests and information needs, which, usually, change over time. The museum institution can no longer fully control the context in which its objects are observed. It can only control the quality and quantity of the metadata provided to assist the interpretation process. Such a realization has driven a handful institutions to make their collections available as open data, generally free access to images allowing reuse, to counteract the poor quality images available on the Internet. The museum can to a certain degree control the selection and use of its collection since users will favour those objects that contain metadata needed to find and interpret them. A query result containing an image and explanatory text makes more sense than only the image or only the text. ${ }^{5}$

Museums are reluctant to make a broad spectrum of their object-metadata available without context and look for a balance between accommodating users and building their own information management system. Oliver (2012) acknowledges that digital objects and collections exist in a vast information space (the Internet) that allows for multiple contexts and interpretations. Access to the objects does not have to be tailored through exhibition design, lectures, guided tours and other educational activities, as traditionally occurs within the physical exhibition space-even though these may be available. Instead, the context provided by the museum is but one of many possible contexts in which the user may find or situate the object. Then what is the role of the museum in this new information space? To answer this question we will first focus on the concept of selection.

Selection takes place at the institution and by the user and can take the form of selecting (or not) an object and a context. From the point of view of the institution, selection is crucial at the moment the digital object is published, placing it in the vast information space with a limited set of metadata. The institution chooses an object (e.g. from the highlights, from the permanent exhibit, from the new

\footnotetext{
${ }^{5}$ For a study of users clicking to view a heritage document, based on contextual information available in viewed summary, see Fachry et al. (2010). They found that "contextual information about the document undoubtedly played an important role in (...) making a selection decision" (p. 48).
} 
acquisitions) with a number of characteristics (e.g. image quality, type of metadata) to be made available. From the point of the user, selection is central when interacting with the metadata. The objects, when properly presented, serve as information documents (e.g. images with a context) that can answer a question or can be repositioned within a new context to further engage in communication. The information chain is thus conceived as a transaction space in which the essential role of the user in completing the information communication is acknowledged. ${ }^{6}$ Only when the object is selected and used as an information carrier can the communication process be said to be completed.

Users select information based on features such as reliability, validity, completeness, actuality, verifiability, relevance and accessibility, depending on the user's background and information need (Boekhorst et al. 2005). ${ }^{7}$ Interestingly, selection of information does not have to be the result of specific queries since users can also 'find' information by accident, through passive search or serendipity (finding something while looking for something else) (Boekhorst et al. 2005). In the digital information space "access of information is the ultimate form of valuation. The selection process that leads to accessing one item represents a synthesis of all other value frameworks" (Navarrete 2010: 7).

Next to digitization of collections, we also see museums participate in the creation of new born digital objects including websites. The increased use of networked media is responsible for a fundamental change in the way visitors come in contact with collections (and museums as their managing institutions). Content, users, institutions and context are all to be found, selected and accessed, within the same information space of the Internet. Therefore, museums, while applying information and communication technology, do not disseminate their content in a broadcast-like fashion to households, as Parry believes (Parry 2007). That is, even if digitization indeed uses a technology with broadcasting media capabilities to reach many people at the same time, it actually combines it with a primarily one-to-one communication style, similar to the telephone network (Keene 1998). It is not the museum that visits the household, but all individual components - the object, collection, museum, or metadata-are placed side by side at the user's disposal in the information space, and only the information that is selected by the user is consumed.

The user thus creates his or her own virtual museum out of the materials available in the digital information space. There is no guarantee that the user will remain within the boundaries of the 'virtual' space set by the museum. In many cases the user will create a superset of metadata, combining metadata provided by the museum with information found elsewhere. An example can be found in Flickr, where users can make multiple collections of images, adding relevant metadata

\footnotetext{
${ }^{6}$ This model was originally used to explain the production and consumption of scientific articles (Mackenzie Owen and Halm 1989).

${ }^{7}$ For an application of the information features to digital heritage, see Navarrete (2013).
} 
hardly ever matching the information provided by the museum. ${ }^{8}$ This turns the museum into a facilitator of information in digital environments, acting as one of the many sources that provide users with objects and metadata with which she creates her personal cultural information space. This might lead to combinatorial innovation, as Varian (2010) argues: the objects, metadata, collections and museums are all considered to be individual components at the user's disposal to be combined at wish. ${ }^{9}$

The relation between the museum and its visitor changes fundamentally as the object, the metadata, the collections, the museums, the museum information system and the user, are all independent components in an information space. HooperGreenhill (2007) argues that "if visitors are offered the evidence from which to draw conclusions, given access to data (...) they are able to adopt a problemsolving approach to learning" (p. 572). She proposes to deconstruct the museum's system of knowledge, highlighting the polysemic nature of objects and allowing multiple readings, in order to allow for personalized systems of communication and learning. Providing digital content as a service would replace the traditional collection-centred, inward-looking data processing model, and turn collections into processes rather than products (Hughes 2011; Peacock 2008; Refland et al. 2007).

It is still a long way to the realization of the new information space conceived here. Museums do not think of the Internet as an environment in which objects, collections and museums all function as discrete objects at the user's disposal. What we mostly see at this moment is an attempt to copy the museum's onsite institutional entity on the Internet. In the long run, this strategy will most likely not be sustainable, as the public will move to spaces where information is presented in an open-reading, re-usable form, if not made by the museum institution then these spaces will emerge from alternative efforts (i.e. the free online encyclopaedia Wikipedia). Museums are rich information spaces and can enhance the information dimension of the Internet. It is undeniable that much has already been achieved by heritage institutions, though their potential has not been realized yet.

The digitization of collections has first of all provided new means of display of and access to existing museum collections. Benefits of digitization are usually based on the use of networked media (the Internet), which allows access from anywhere anytime anyhow. Objects can be accessed at home on a desktop at night or on the street from a mobile phone during holidays, freeing constraints of opening

\footnotetext{
${ }^{8}$ The Flickr Commons is a project launched in 2008 for heritage institutions to publish their collections in a "safe and regulated space" (Kalfatovic et al. 2009: 268). The main goal is to increase access to collections (Flickr 2015). Some museums may want to lock their online visitors into their Online Museum experience, in hope of maintaining control of the context (Marty 2011). ${ }^{9}$ Varian (2010) uses as example the Internet: "it offered a flexible set of component technologies which encouraged combinatorial innovations" (p. 2). Its component parts are all bits (e.g., programming languages, protocols, standards, software libraries, productivity tools) that could be sent around the world with no manufacturing time, no inventory management, and no sipping delay. That is why innovation has had such rapid pace.
} 
hours, location and selection available at the exhibition halls. On the Web, an object can be presented in many different ways at the same time, with different contexts and interpretations, independent from its location in a museum. Furthermore, digitization permits a dynamic form of documentation where interpretation can be edited and extended. New systems to order and manage objects give preference to changing and layered readings, emphasising individual meaning-making, including terms that liberate objects from the straightjacket of predefined frames of reference (Parry 2007).

\section{The Tangible, Intangible and E-Tangible Object}

Museums have always revolved around the objects in their collections and will continue to do so in the future, with the difference that digital objects will become more and more part of their collections. Even when benefits are accepted, including personalization, reuse, and access of otherwise not accessible materials (in high detail view, because of its fragility, or simply because of living in another part of the world); many museum experts continue to emphasize the irreplaceable nature of the original (Economou 2008).

Since museums are about physical and real objects, the digital and virtual have been conceptualized in opposition of it. Cameron observes that physical objects determine the classificatory framework in which objects are interpreted, so that digital objects exist only in relation to the physical "seizing the real, suspending the real, exposing the real, knowing the real, unmasking the real" (Cameron 2007: 69). However, there are other ways to conceptualize digital objects. Parry (2007) proposes a broader definition of objects when stating that objects in museums are "discrete, contained units of human experience, identified and extracted in order to help substantiate (to evidence), record or define an individual or collective epistemology (system of knowledge) or ontology (sense of being)" (p. 57). This definition, he argues, liberates objects from being real, copies, digital, information, and so one; instead it defines objects in accordance with their nature as tangibles, intangibles and e-tangibles (Witcomb 2007). ${ }^{10}$ As we have argued from the start, all objects are carriers of information, and there are good reasons for doing so. It supersedes thinking in terms of the dichotomy of the digital and the non-digital, the virtual and the real and the copy and the original, allowing an understanding of objects as independent from technology and institutional context. It furthermore explains how interaction with objects and the user's active role in constructing knowledge emerged more or less naturally. Museums have been complex information management institutions all along, rather than collecting and ordering physical

\footnotetext{
${ }^{10}$ Witcomb (2007) suggests to define digital objects in terms of the way collections are accessed: through onsite kiosks (one of the most popular early applications for digital objects), visualizing three-dimensional and virtual reality exhibits (a variation of the kiosk made 3D), post-visit souvenirs (take away products such as the DVD), mobile computing and handheld devices (personalized and customizable kiosks), and on the Web.
} 
objects they have always been collecting and ordering information (Parry 2007). Digitization merely brought the object's nature as a polysemic informational carrier to the surface.

Over the past decades, the international community has defined tangible, intangible and digital heritage. Heritage refers to the legacy inherited from past generations embodied in physical artefacts, monuments and places (tangible), in traditions and living expressions (intangible), and in digital information resources (e-tangible). These digital information resources can include single objects (e.g. digital image), but also databases (e.g. collections of images) and the software to allow their access. UNESCO has made legally binding agreements among the States Parties to the Conventions about the preservation of tangible and intangible heritage (the UNESCO World Heritage Convention from 1972, the Convention for the Safeguarding of Intangible Cultural Heritage, adopted in 2003, and the Convention on the Protection and Promotion of Diversity of Cultural Expressions, adopted in 2005). International agreements about digital heritage have only been left at the recommendation stage (the UNESCO Charter on the Preservation of Digital Heritage, adopted in 2003). Long and short-term access to objects has been considered fundamental in all the drafted Conventions, not only in their introductory goals but throughout the measures proposed. Maybe this reflects the tendency that, while museum work revolves around objects, objects are more and more considered to be information carriers, either as tangible, intangible or e-tangible object. Defining an object tangible or intangible (or e-tangible) has consequences for its preservation. For instance, the sound of music can be defined as intangible unless the goal is to document the carrier (e.g. LP) in which case it becomes tangible. When the object is defined as intangible, migration into new medium is used to ensure continuous accessibility. However, definitions are not straightforward, as we have argued, due to the polysemic nature of objects that allows multiple meanings and multiple readings so that a digital recording of a concert can be tangible (physical location where file is stored), intangible (sound of music) and e-tangible (no need to digitize).

\section{Conclusion}

To increase the access to and use of objects, both now and in the foreseeable future, a policy on metadata is of crucial importance. Museums have collections of objects that can be read in different ways. The process of digitization has brought the polysemic nature of the object as information carrier to the fore. The context in which the object is interpreted is determined by the metadata provided. The user depends on metadata to interpret objects and she will select the object with the metadata that is most likely to satisfy his interest or information need. Museums can support and increase the use and interpretation of their objects by enriching their metadata. Practices of documentation, indexing and enrichment of metadata have to be adjusted to the new information space in which users interact and add self created content. The fragmented presence of museum collections in the information 
space on the Internet might lead to new and surprising viewpoints on objects and their relations. In the digital information space, objects, metadata, collections, museums and users, all exist as independent nodes in a vast universe of data. In such an environment, objects are selected based on their accessibility and potential to satisfy personal information needs. The origin of the object and its related metadata is no longer of interest to the user accessing the object on the Internet, for the Internet has become origin and context of all objects and their relations. All of this does not mean that the museum as an institution may become redundant in the digital world. For, as Parry argues, trust may be key in the way the user experiences collections: "Knowing (and caring) about the difference between a collection of digital things that appears like a museum, and a museum that is presenting digital things based on its collection, comes down to questions of trust and definitions of authenticity" (Parry 2007: 68).

A metadata policy will help museums face the challenge to find their place in the new information space. Naturally, it would seem, the museum would serve as a node in a network connecting objects, information, people and places. This requires opening up to information exchange, transgressing the institutional boundaries in virtual spaces where new collections are being created. Only then can museums truly provide access to their objects.

Open Access This chapter is distributed under the terms of the Creative Commons AttributionNoncommercial 2.5 License (http://creativecommons.org/licenses/by-nc/2.5/) which permits any noncommercial use, distribution, and reproduction in any medium, provided the original author(s) and source are credited.

The images or other third party material in this chapter are included in the work's Creative Commons license, unless indicated otherwise in the credit line; if such material is not included in the work's Creative Commons license and the respective action is not permitted by statutory regulation, users will need to obtain permission from the license holder to duplicate, adapt or reproduce the material.

\section{References}

Baca, M., Coburn, E., \& Hubbard, S. (2008). Metadata and museum information. In P. Marty \& K. B. Jones (Eds.), Museum informatics. People, information, and technology in museums (pp. 107-128). London: Routledge.

Bearman, D. (2008). Representing museum knowledge. In P. Marty \& K. B. Jones (Eds.), Museum informatics. People, information, and technology in museums (pp. 35-58). New York: Routledge.

Bennet, T. (1992). The birth of the museum. London: Routledge.

Bennet, T. (1995b). Useful culture. Cultural Studies, 6(3), 395-408.

Beumer, M. (2009). Capturing museum knowledge. A twenty year evolution in digitally recording the Tropenmuseum collection. Amsterdam: KIT Publishers.

Boekhorst, A., Kwast, I., \& Wevers, D. (2005). Informatievaardigheden. Utrecht, The Netherlands: Lema.

Buckland, M. (1997). What is a document? Journal of the American Society of Information Science, 48(9), 804-809. 
Cameron, F. (2007). Beyond the cult of the replicant-Museums and historical objects: Traditional concerns, new discourses. In F. Cameron \& S. Kenderdine (Eds.), Theorizing digital cultural heritage. A critical discourse (pp. 49-76). Cambridge, MA: MIT.

Economou, M. (2008). A world of interactive exhibits. In P. Marty \& K. B. Jones (Eds.), Museum informatics. People, information, and technology in museums (pp. 137-156). New York: Routledge.

Fachry, K. N., Kamps, J., \& Zhang, J. (2010). The impact of summaries: What makes a user click? In Proceedings of the 10th Dutch-Belgian Information Retrieval Workshop (DIR 2010) (pp. 47-54). Nijmegen, The Netherlands: Radboud University Nijmegen.

Flickr. (2015). Retrieved from https://www.flickr.com/commons

Grognet, F. (2007). Ethnology: A science on display. In B. Carbonell (Ed.), Museum studies. An anthology of contexts (pp. 175-180). Malden, MA: Blackwell Publishing.

Hooper-Greenhill, E. (1992). Museums and the shaping of knowledge. London: Routledge.

Hooper-Greenhill, E. (2007). Changing values in the art museum: Rethinking communication and learning. In B. Carbonell (Ed.), Museum studies. An anthology of contexts (pp. 556-675). Malden, MA: Blackwell Publishing.

Hughes, L. (2011). Introduction: The value, use and impact of digital collections. In L. Hughes (Ed.), Evaluating and measuring the value, use and impact of digital collections (pp. 1-10). London: Facet Publishing.

Kalfatovic, M. R., Kapsalis, E., Spiess, K. P., Van Camp, A., \& Edson, M. (2009). Smithsonian Team Flickr: A library, archives, and museums collaboration in web 2.0 space. Archival Science, 8(4), 267-277.

Keene, S. (1998). Digital collections: Museums and the information age. Oxford, England: Butterworth-Heinemann.

Legêne, S. (2008). Flatirons and the folds of history. On archives, cultural heritage and colonial legacies. In S. Wieringa (Ed.), Traveling heritages. New perspectives on collecting, preserving and sharing women's history (pp. 47-64). Amsterdam: Aksant.

Leone, M., \& Little, B. (2007). Artifacts as expressions of society and culture. Subversive genealogy and the value of history. In B. Carbonell (Ed.), Museum studies. An anthology of contexts (pp. 362-374). Malden, MA: Blackwell Publishing.

London Charter. (2009). Retrieved from http://www.londoncharter.org/

Mackenzie Owen, J. (2007). The scientific article in the age of digitization. Dordrecht, The Netherlands: Springer.

Mackenzie Owen, J., \& van Halm, J. (1989). Innovation in the information chain: The effects of technological development on the provision of scientific and technical information. London: Routledge.

Marty, P. (2008). Information representation. In P. Marty \& K. B. Jones (Eds.), Museum informatics. People, information, and technology in museums (pp. 30-34). New York: Routledge.

Marty, P. (2011). My lost museum: User expectations and motivations for creating personal digital collections on museum websites. Library and Information Science Research, 33(3), 211-219.

Marty, P., \& Jones, K. B. (2008). Museum informatics. People, information, and technology in museums. New York: Routledge.

McClellan, A. (2008). The art museum, from Boulée to Bilbao. Berkeley: University of California Press.

Navarrete, T. (2009). An outsider's perspective. In M. Beumer (Ed.), Capturing museum knowledge. A twenty year evolution in digitally recording the Tropenmuseum collection (pp. 69-78). Amsterdam: KIT Publishers.

Navarrete, T. (2010). Does digitization bring a productivity lag in museum work. In Association of Cultural Economics International Annual Conference 2010 (ACEI). Retrieved from http://hdl. handle.net/11245/2.127002

Navarrete, T. (2013). Digital cultural heritage. In I. Rizzo \& A. Mignosa (Eds.), Handbook of cultural economics (pp. 251-271). Cheltenham, England: Edward Elgar. 
Navarrete, T., \& Mackenzie Owen, J. (2011). Museum libraries: How digitization can enhance the value of the museum. Palabra Clave (La Plata), 1(1), 12-20.

Noordegraaf, J. (2004). Strategies of display. Museum presentation in nineteenth- and twentiethcentury visual culture. Rotterdam, The Netherlands: NAI.

Oliver, G. (2012). The digital archive. In L. Hughes (Ed.), Evaluating and measuring the value, use and impact of digital collections (pp. 49-60). London: Facet Publishing.

Parry, R. (2007). Recoding the museum. London: Routledge.

Peacock, D. (2008). The information revolution in museums. In P. Marty \& K. B. Jones (Eds.), Museum informatics. People, information, and technology in museums (pp. 59-76). New York: Routledge.

Refland, S., Tuters, M., \& Cooley, J. (2007). Geo-storytelling: A living archive of spatial culture. In F. Cameron \& S. Kenderdine (Eds.), Theorizing digital cultural heritage. A critical discourse (pp. 409-416). Cambridge, MA: MIT.

Varian, H. (2010). Computer mediated transactions. In Ely Lecture at the American Economics Association Meeting, Atlanta, GA.

Wikipedia. (2015). Retrieved from http://en.wikipedia.org/wiki/Information_architecture

Witcomb, A. (2007). The materiality of virtual technologies: A new approach to thinking about the impact of multimedia in museums. In F. Cameron \& S. Kenderdine (Eds.), Theorizing digital cultural heritage. A critical discourse (pp. 35-48). Cambridge, MA: MIT. 